\title{
EXPERT ANALYSIS OF THE FLOOR EXERCISE TRAINING SYSTEM
}

\author{
Marina Petrova
}

Summary

The routines of floor exercise are a combination of choreography, acrobatic and gymnastic exercises. A research by $S$. Borissenko (2000) reveals the percentage ratio between these interconnected parts. Predominantly the highest percentage is the choreographic movements $-71.4 \%$. The latest changes in the gymnastics rules direct attention to the specialists to the attractiveness and artistry of the gymnastic combinations of this apparatus. When the gymnast performing her routines, she has to demonstrate her abilities and turn the well-composed composition into a "performance". In this performance, she has to demonstrate good choreography, artistry, expressiveness, musicality and perfect technique. The positions of Bulgarian athletes in this gymnastics discipline in recent years are not very good. This has directed us to study the causes of the weak results and optimize the preparation in a multi-annual aspect, according to the new global trends. The analysis of the routines of the best gymnasts in Bulgaria and in the world showed that the results of our athletes are logically related to our whole system of training for floor exercise, which needs to be optimized.

Key words: floor exercise, difficulty, technical regulations

\section{Introduction}

The floor exercise is one of the most difficult disciplines of the female gymnasts. It is characterized by progressive development in three directions: difficulty in exercises and combinations, composition and performance. The contents of the combination include acrobatic exercises in series, relations from gymnastic exercises and movements (Dobreva, Ts., 2007a). A research by S. Borissenko (2000) reveals the percentage ratio between these interconnected parts. Predominantly the highest percentage is the choreographic movements $-71.4 \%$, in which authors includes the jumps, leaps, turns and spins, connecting elements such as poses and movements with the body and limbs. According to the same study, 25\% used the acrobatic exercises, which are the basis of the difficulty and the requirements for composition of the routines. The quantity of the exercises on the floor exercise are these with which every gymnastics training begins. It is necessary to accumulate a volume of basic motor actions on which depends the level of technical training (Dimitrova, B., 2015b). The latest changes in the gymnastics rules direct attention to the specialists to the attractiveness and artistry of the gymnastic combinations of this apparatus. When the gymnast performing their routines, she has to demonstrate her abilities and turn the well-composed composition into a "performance" (Smolevskiy, V, Gaverdovskiy, 1999). In this performance, she has to demonstrate good choreography, artistry, expressiveness, musicality and perfect technique (Dobreva, Ts., 2007b). The positions of Bulgarian athletes in this gym- nastics discipline in recent years are not very good (Dimitrova, B. \& Petrova, M., 2013, Dimitrova, B., 2015a).

\section{Aim and Objectives of the study}

Therefore the aim of our study is to establish objective criteria reasons for the poor performance of this apparatus and to optimize the training system. To achieve the goal we set ourselves the following tasks:

1. To record and analyze the combinations of Bulgarian gymnasts and those of the global elite

2. To make a comparative analysis of volume material utilized for different age groups.

3. To suggest changes in training program in multi-aspect.

\section{Methods}

In the course of our work we used the methods of recording and observation, expert analysis, comparative analysis and statistical methods. The objective of our study is 207 combinations covering five age groups - junior girls, senior girls, girls, and cadets completed in the state championships in 2017 and the finalists' combinations of this apparatus of the European Championship for Girls in 2016 in Bern. The subject of the study is the difficulty and the selected exercises included in the composition and performed by the athletes. 


\section{Results}

In the first age group - girls up to 9 years of age, gymnasts perform a compulsory combination. It includes 8 acrobatic exercises - round-off and two flic-flac in connection, walkover backward, handstand, handspring, walkover and flic-flac to one leg. These exercises formed the difficulty of the combination. The gymnastic exercises include $-1 / 1$ turn $\left(360^{\circ}\right)$, stretched hop with $1 / 1$ turn $\left(360^{\circ}\right)$, leap with alternate leg change and two split leap fwd (leg separation $180^{\circ}$ ). They are not involved in the difficulty, but if they are not met, it takes $0.5 \mathrm{p}$. for each. The analysis of 74 executed combinations shows that $52.7 \%$ of gymnasts perform all requirements others have included only some of the difficult exercises (Figure 1). The largest percentage - $24.33 \%$ have executed 5 of the requirements, with two flicflac and flic-flac to one leg missing, while $10.81 \%$ do not include in the combination handspring or handstand.

The technical training standards for this age according to our Single Program (Dimova, Tsv. et al., 1988) are as follows:

1. For 7-8 year olds:

- Round-off;

- Handspring;

- $1 / 1 \operatorname{turn}\left(360^{\circ}\right)$;

- $\quad$ Flic-flac;

- Handstand (keeping).

2. The 8-9 year olds are added;

- Round-off, Flic-flac;

- Power lifting to handstand an outwardly open angle;

- $\quad$ Leap with maximum amplitude.

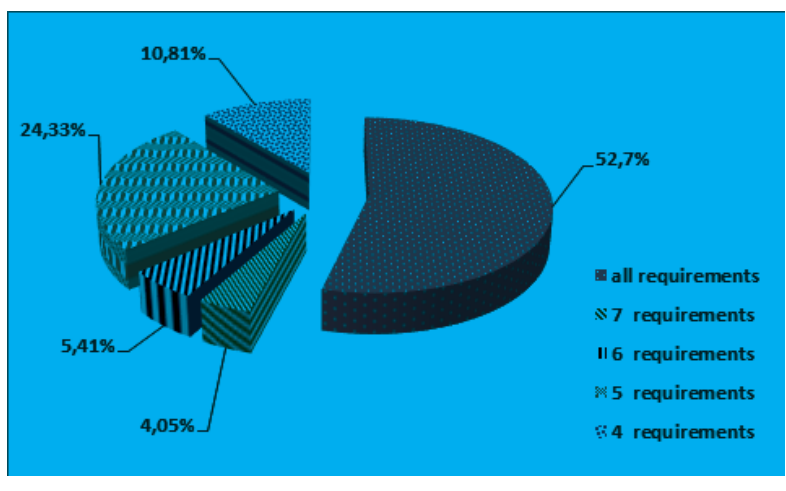

Fig.1 Performed requirements - girls up to 9 years old

Comparing the compulsory combination according to the ordinance of the Bulgarian Gymnastics Fed- eration for 2017 and the Single Program, it seems that the requirements correspond to the volume of material that should be studied at that age.

The next age group is senior girls (10-11 year olds) who also play a compulsory program, but the difficulty is greater. The exercises that form the difficulty (9 pieces) are round-off, flic-flac and salto backward stretched in series, power lifting to handstand, handspring-salto forward tucked, round-off, flic-flac and salto backward tucked. Only 46.15\% of the 52 combinations studied play with the full age requirements (Figure 2). The remaining gymnasts do not execute all the difficult exercises, with $17.3 \%$ perform 8 requirements, most of which do not make the power lifting to handstand. At $11.54 \%, 2$ difficult exercises missing - salto backward stretched and handspring or salto backward tucked. The same percentage of gymnasts $11.54 \%$ plays only 3 of the requirements they are two round-off and flic-flac or handspring. For most gymnasts the problem is mainly the salto backward and forward. This could be corrected the attention by focusing on mastering the trampoline volume material presented in the unified program.

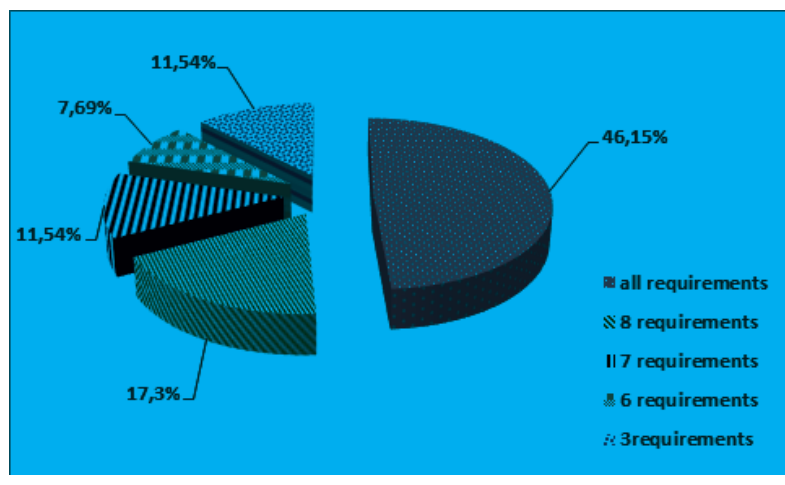

Fig.2 Performed requirements - girls 10-11 years old

In the comparative analysis of the technical norm provided in the single program and the compulsory combination for this age, we note that the requirements do not differ significantly, which is a prerequisite for the growth of young gymnasts. Whereas, less time to master volume of material than 10 -year olds leads to a failure to meet the higher requirements.

In the group of girls younger (12-13 year old) gymnasts execute a voluntary program with compulsory requirements. There are two leaps, one of them cross/side split position $\left(180^{\circ}\right), 1 / 1$ turn $\left(360^{\circ}\right)$ on one leg, salto forward and backward, a type of salto 
with difficulty at least „C“, a group „B“ final exercise. The analysis of the executed combinations shows a reduction in the percentage of gymnasts mastered the prescribed technical requirements under an ordinance. Only $27.27 \%$ of the gymnasts play with all requirements (Figure 3), and a small part of them are included in difficult exercises. At $24.24 \%$ of the competitors lack one of the requirements - group "C" salto (eg. salto forward stretched with $1 / 1$ twist$360^{\circ}$, salto backward stretched with $1 \frac{1}{1 / 2}$ twist $-540^{\circ}$ ). The highest percentage $-30.3 \%$ have executed 3 of the requirements, as well as salto from "C", there is also missing a group „B“ finals (eg. salto forward stretched, salto backward stretched with $1 / 2$ twist$180^{\circ}$ or $1 / 1$ twist $-360^{\circ}$ ). The percentage of the exercises executed by difficulty groups is the following: the highest percentage is the exercises of groups "C“ and „A“- respectively $46.95 \%$ and $36.64 \%$. Exercises from group "C" are present in the combinations of $14.88 \%$ of the gymnasts, with $9.92 \%$ of them being gymnastics and only $4.96 \%$ acrobatic. It gives the impression, that with each subsequent age the number of gymnasts participating in competitions decreases, which makes competition weaker and is probably the reason for the shown poor results. This requires us to change the system of competition. It would be good to include different levels of training for adolescents. This will reserve those competitors who acquired the volume material more slowly and will not progressively reduce the number of sports gymnasts.

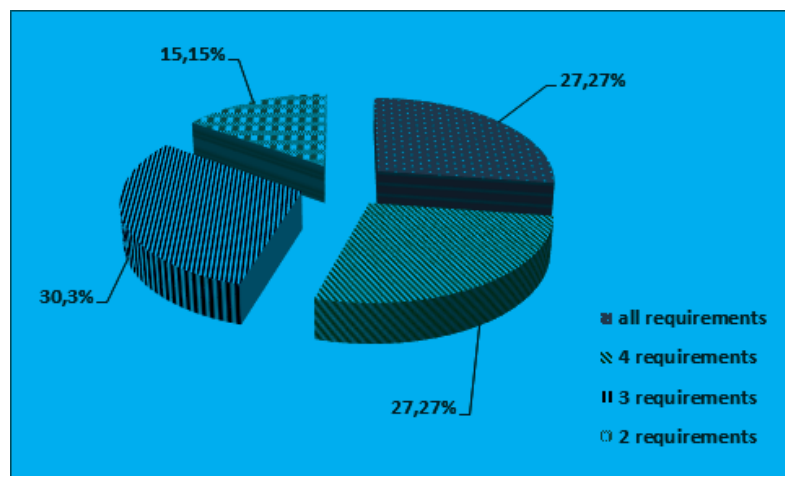

Fig. 3 Performed requirements - junior girls 12-13 years old

The analysis of the difficulty of routines senior girls and cadets showed that the mastered exercises by our gymnasts and composed the combinations according to their ability are not competitive and promising to enter the world elite. This, in our opinion, is due to program gaps analyzed for precedent ages. The average difficulty of the routines of the finalists on floor exercises of the European Championships for junior 2016 in Bern is 4,837 points and our contestants in the state championship in 2017 are 2,536 points as our best gymnasts for this age rating is 4,075 points. The shown difference is very large and reveals the lack of perspective of our gymnasts.

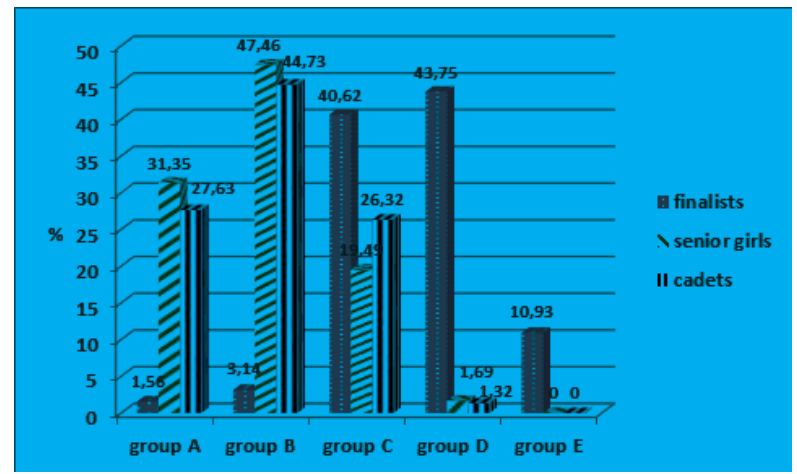

Fig. 4 Exercises in groups of difficulty

The tracking of the group difficulty in our juniors and cadets and the world elite at the studied age confirms the established weaknesses in the mastered of volume material. In our gymnastics, the exercises used are mainly of the „A“ groups $-31.35 \%$, „B“ $-47.46 \%$ and „C“ $-26.32 \%$ (Figure 4), while the finalists are the highest of group "D“ $-43.75 \%$ and "C" $-40.62 \%$. At routines to gymnasts of the world elite, there are also exercises of group " $\mathrm{E}^{\text {, }}$ which are of higher value and make up $10.93 \%$ of their compositions. This is very indicative of the technical level of this apparatus of Bulgarian competitors.

\section{Discussion}

The analyzed routines and the research of the difficulty of the acquired the volume material of the exercises at the stage of the multi-year preparation on floor exercises device revealed the available weaknesses as well as the reasons for them. This allowed us to offer adjustments to the system of preparation to achieve the desired result. Changes should be directed to both the organization of the preparation and the system of selection that are interrelated. The study showed that the requirements of ordinance and a unified program allow the construction of a gymnast who is ready for high sporting results. The gradual reduction of competitors who successfully absorb the volume material and reach the required technical level for age requires changes. These will be achieved with the following adjustments in the training system: 
- Increase the number of children involved in gymnastics by adding new age groups seven and eight year olds;

- In the following ages, to be included in competitions gymnasts at different racing levels according to certain technical requirements in accordance with their capabilities;

- Increase volume material from groups of difficulty $\mathrm{C}, \mathrm{D}$ and $\mathrm{E}$ at our best gymnasts in the age of junior and cadets.

\section{References}

Borisenko, S. (2000), Povishenie izpulnitelskogo masterstva gimnastok na osnove sovershenstvovaniya horeograficheskoi podgotovki, Disertatcia, Sankt-Peterburg.

Dimitrova, B. (2015a), Expert analysis of the training system of the beam, Activities Physical Education and
Sport, Vol. 05, № 1, pp. 50-52.

Dimitrova, B. (2015b), Sistema za podgotovka i optimizirane na obuchenieto $v$ sportnata gimnastika zheni, B-INS, Sofia

Dimitrova, B., Petrova, M. (2013), Actualizirane na sistemata na podgotovka na smesena usporedka, Sport \& Nauka (extra issue №2), Sofia, s. 112-118.

Dimova, Tsv. et al. (1988), Edinna programa I metodika za obuchenie I trenirovka, Bulgarska Federatsiya Gimnastika, Sofia.

Dobreva, Tsv. (2007a), Podgotovkata $v$ sportnata gimnastika (v pomosght na treniora), B-INS, Sofia

Dobreva, Tsv. (2007b), Sistema za podgotovka na gimnastichkite v sportnata gimnastika, Bulgarska Federatsiya Gimnastika, Sofia.

Smolevski, V., \& Gaverdovski, Y, (1999), Sportivnaya gimnastika, Olimpiiskaya literatura, Kiev.

Head Assist. Marina Petrova, PhD

National Sports Academy

Department of Gymnastics

Studentski grad, 1700 Sofia, Bulgaria

E-mail: maripet@abv.bg 